\title{
CLINICAL PROFILE OF HYPONATRAEMIC PATIENTS AND ASSOCIATED RISK FACTORS IN A TERTIARY CARE HOSPITAL IN GOA
}

\author{
Aditya Mulgaonkar1, Khandeparkar Anar2, Khandeparkar Viraj ${ }^{3}$ \\ ${ }^{1}$ Senior Resident, Department of Medicine, Goa Medical College, Bambolim, Goa. \\ ${ }^{2}$ Associate Professor, Department of Medicine, Goa Medical College, Bambolim, Goa. \\ ${ }^{3}$ Associate Professor, Department of Medicine, Goa Medical College, Bambolim, Goa.
}

\section{ABSTRACT}

\section{BACKGROUND}

Hyponatraemia as a clinical entity is very common, yet published literature contains only few descriptive hospital based studies from India and it has never been studied in our hospital which is the only teaching hospital in the state of Goa.

\section{MATERIALS AND METHODS}

We did a cross-sectional study on the various clinical manifestations and underlying aetiologies in consecutive patients admitted to the General Medicine wards in Goa Medical College and Hospital.

\section{RESULTS}

Majority of patients were above 50 years of age (mean age $59.4 \pm 18.1$ years) with overall male preponderance (56\% vs. $44 \%$ ), but an excess of females in the severe hyponatraemia category. Majority were euvolaemic (46.7\%). Among the aetiological factors, SIADH was the commonest cause (40\%) followed by diuretic use (38.6\%). Majority of patients had severe hyponatraemia $(\leq 120$ $\mathrm{mEq} / \mathrm{L})$. Predominant presentation was with neurologic symptoms $(69.33 \%)$.

\section{CONCLUSION}

Hyponatraemia is a common electrolyte disorder for which there should be a high degree of suspicion in patients presenting with neurologic symptoms, especially among the elderly. An expanded study including the whole hospital patient population would help throw light on other common aetiologies and aid in better understanding and management of such patients.

\section{KEYWORDS}

Hyponatraemia, Clinical Profile, Aetiology, Tertiary Care Hospital.

HOW TO CITE THIS ARTICLE: Mulgaonkar A, Anar K, Viraj K. Clinical profile of hyponatraemic patients and associated risk factors in a tertiary care hospital in Goa. J. Evolution Med. Dent. Sci. 2017;6(28):2311-2314, DOI: 10.14260/Jemds/2017/497

\section{BACKGROUND}

Hyponatraemia is defined as a serum sodium concentration < $135 \mathrm{mEq} / \mathrm{L}^{1}{ }^{1}$ It is the commonest electrolyte disorder encountered in clinical practice with incidence of $0.97 \%$ and prevalence of $2.48 \%$ in hospitalised adult patients when the cut-off level is taken as $130 \mathrm{mEq} / \mathrm{L}^{2}$ and $15 \%-30 \%$ when cut-off level is $135 \mathrm{mEq} / \mathrm{L}^{3}$ Hyponatraemia can be classified as true (hypo-osmolar) hyponatraemia or pseudohyponatraemia. True hyponatraemia is further classified as hypo-, eu- and hypervolaemic hyponatraemia. The aetiologies are diverse and often a combination of causes is present in a given patient. Spectrum of symptoms ranges from apathy and anorexia to seizures and coma. ${ }^{4}$ Hyponatraemia increases the risk of falls and fractures in the elderly. ${ }^{5}$

Though a large number of papers on various aspects of hyponatraemia are available to readers, few papers actually deal with hospital patterns of aetiologies and clinical presentations of hyponatraemic patients with even fewer from India. Clinico-aetiologic profile of hyponatraemic

Financial or Other, Competing Interest: None.

Submission 27-02-2017, Peer Review 22-03-2017,

Acceptance 30-03-2017, Published 06-04-2017.

Corresponding Author:

Aditya Mulgaonkar,

Ashirwad, H. No. 711/29,

Green Hill, Socorro,

Porvorim, Bardez, Goa-403501.

E-mail: adityamulgaonkar@gmail.com

DOI: $10.14260 /$ jemds $/ 2017 / 497$ patients has never been studied before in the state of Goa and hence this study was undertaken.

\section{MATERIALS AND METHODS}

This observational cross-sectional study was carried out in Goa Medical College and Hospital, the only teaching hospital in the state of Goa. Consecutive patients admitted from January 2012 to September 2013 were selected.

\section{Inclusion Criteria}

1. Serum sodium $<135 \mathrm{mEq} / \mathrm{L}$ at admission (confirmed by repeat testing).

2. Corresponding blood glucose level done on a fluoride bulb sample (to correct for hyperglycaemia).

3. Serum and urine osmolality obtained before starting any treatment for hyponatraemia.

4. Hyponatraemia confirmed as true (hypo-osmolar) hyponatraemia.

\section{Exclusion Criteria}

1. Patients whose admission serum sodium was $\geq 135$ $\mathrm{mEq} / \mathrm{L}$ and who developed low serum sodium later in hospital.

2. Treatment with intravenous fluid already given before required blood samples obtained.

3. Initial blood glucose level not obtained (hence correction for hyperglycaemia not possible).

4. High or normal serum osmolality. 
The study was approved by the Ethics Committee of Goa Medical College and Hospital. Corrected sodium values were calculated if hyperglycaemia was detected on admission reports by the formula: corrected sodium $(\mathrm{mEq} / \mathrm{L})=$ measured sodium $(\mathrm{mEq} / \mathrm{L})+[1.6 \times$ \{ (blood glucose level in $\mathrm{mg} / \mathrm{dL}-100) / 100\}]$.

Data obtained included demographic characteristics, symptoms (classified further as mild/moderate/severe), ${ }^{4}$ pre-existing diseases, physical signs and a battery of investigations (biochemical, haematological, imaging and urinalysis). Assessment of volume status was done according to clinical criteria ${ }^{6,7}$ as follows:

- Hypovolaemia: Oedema, pulmonary rales, ascites, jugular venous distention, positive hepatojugular reflux, hypertension.

- Hypervolaemia: Orthostatic hypotension (Drop in systolic blood pressure $>20 \mathrm{mmHg}$ or drop in diastolic blood pressure $>10 \mathrm{~mm} \mathrm{Hg}$ measured three minutes after standing up from supine position), reduced pulse volume, reduced jugular venous pressure, loss of axillary sweat, reduced skin turgor, dry mucous membranes.

- Euvolaemia: no signs of either hypovolaemia or hypervolaemia.

Most of the biochemical investigations were done on ARCHITECT c8000 and ARCHITECT c4000 auto-analysers (Abbott Inc. USA). Thyroid function tests were done on I2000SR machine

(Abbott Inc. USA). Serum sodium measurement technique was indirect ion-selective electrode (diluted). All tests were done in the biochemistry laboratory of our hospital.

\section{RESULTS}

75 patients were studied. 42 were males (56\%) and 33 females $(44 \%)$ with mean age $59.4 \pm 18.1$ years (mean age for males 57.04 years and for females 62.06 years). Other data is presented in following tables:

\begin{tabular}{|c|c|c|c|c|}
\hline Symptoms & CNS* & GI $\dagger$ & Musculoskeletal & Asymptomatic \\
\hline No. of patients (\%) $(\mathrm{n}=75)$ & $52(69.33 \%)$ & $49(65.33 \%)$ & $12(16 \%)$ & $7(9.33 \%)$ \\
\hline \multicolumn{4}{|c|}{ Table 1. Distribution of Symptoms by Organ System } \\
\hline
\end{tabular}

*Central Nervous System †Gastrointestinal

\begin{tabular}{|c|c|}
\hline Symptom*† & No. of Patients (\%) $(n=52)$ \\
\hline Apathy & $3(5.76 \%)$ \\
\hline Headache & $4(7.69 \%)$ \\
\hline Lethargy & $18(34.6 \%)$ \\
\hline Agitation & $3(5.76 \%)$ \\
\hline Ataxia & $2(3.84 \%)$ \\
\hline Confusion/disorientation & $27(51.92 \%)$ \\
\hline Seizures & $7(13.46 \%)$ \\
\hline Drowsiness/stupor & $8(15.38 \%)$ \\
\hline Coma & $2(3.84 \%)$ \\
\hline
\end{tabular}

*Multiple symptoms often overlap in a given patient †In order of increasing symptom severity

\begin{tabular}{|c|c|}
\hline Volume Status & No. of Patients (\%) (n = 75) \\
\hline Hypovolaemic & $15(20 \%)$ \\
\hline Euvolaemic & $35(46.7 \%)$ \\
\hline Hypervolaemic & $25(33.3 \%)$ \\
\hline \multicolumn{2}{|c|}{ Table 3. Distribution of Patients by Volume Status } \\
\hline
\end{tabular}

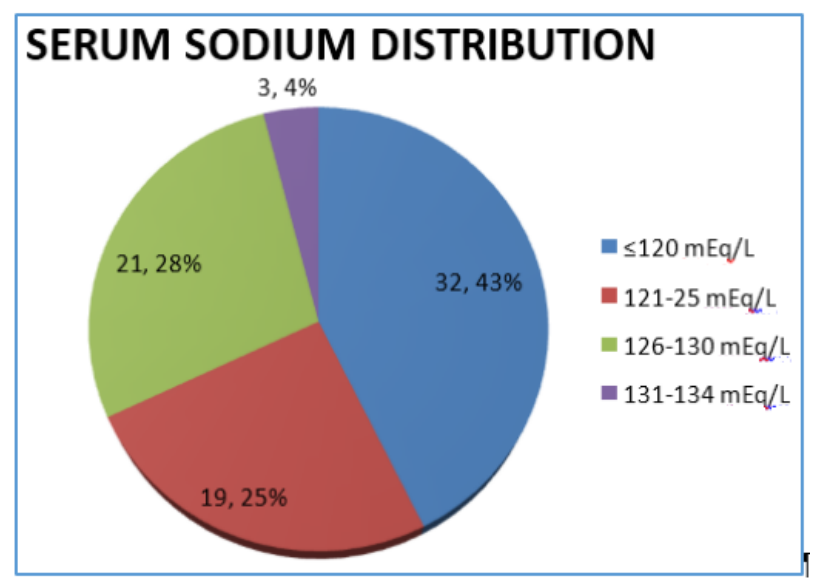

Figure 1. Distribution of Patients among Different Levels of Serum Sodium $(n=75)$. Mean $\pm S D=120.8 \pm 7.79 \mathrm{mEq} / \mathrm{L}$

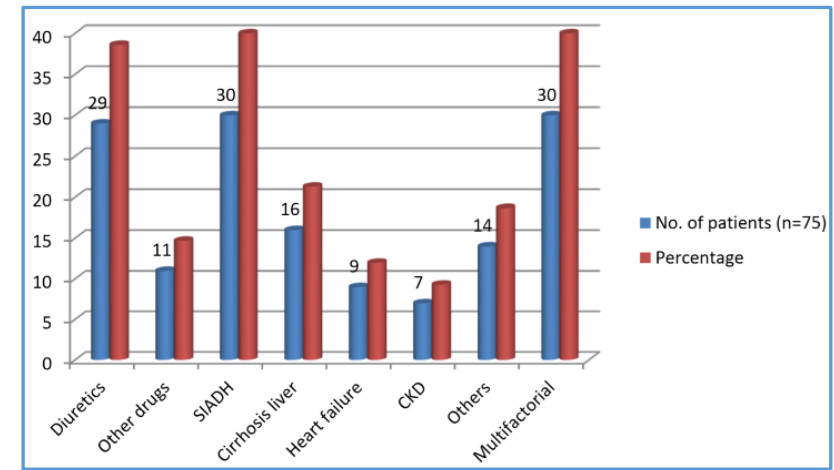

Figure 2: Aetiology of Hyponatraemia

Various drugs taken together account for $53.33 \%$ of cases of hyponatraemia. These include loop diuretics- 15 patients (20\%), thiazide diuretics- 13 patients (17.3\%), diuretic combinations- 9 patients (12\%), angiotensin receptor blockers (ARB)- 11 patients (14.66\%), calcium channel blocker (CCB)- 4 patients (5.33\%), antipsychotics- 4 patients (5.33\%), antidepressants- 1 patient (female) and miscellaneous.

Mean age of patients on diuretics was 62.4 years and their mean serum sodium was $118.58 \mathrm{mEq} / \mathrm{L} ; 28$ patients $(37.3 \%)$ were on salt restricted diet. Only one patient had glucocorticoid insufficiency (resulting from unintentional withdrawal of steroid after chronic use for 4 years).

\section{DISCUSSION}

In our study majority of the patients were elderly ( $\geq 60$ years) and mean age of females was higher (62.06 years) than that of males (57.04 years), which is consistent with other studies.8,9,10,11 But Agarwal et al ${ }^{12}$ found a mean age of 48.1 years and Chowdhury et al ${ }^{13}$ mentioned $46-64$ years as the most common age group, which differ from our findings probably because of different patient populations studied. Males usually outnumber females in hospital admissions, which explains greater number of male patients in the study. 
Shapiro et $\mathrm{al}^{14}$ from Israel and Rao et $\mathrm{al}^{10}$ reported an excess of females in their studies for severe hyponatraemia (serum sodium $\leq 125 \mathrm{mEq} / \mathrm{L}$ ) in the elderly ( $\geq 60$ years), which matches a corresponding subanalysis in our study $\{31$ patients $\geq 60$ years and having serum sodium $\leq 125 \mathrm{mEq} / \mathrm{L}$ of which 18 are females (58.1\%)\}.

Asymptomatic patients accounted for only $9.33 \%$ of our study population. Majority had neurologic symptoms of moderate severity with confusion/disorientation being the most common (51.92\%). This can be attributed to the fact that the majority $(43 \%)$ had severe hyponatraemia $(\leq 120$ $\mathrm{mEq} / \mathrm{L})$, at which level neurologic manifestations predominate.

Volume status determination by a combination of variables is a basic step in classifying and identifying possible aetiologies of low serum sodium. Majority of patients were euvolaemic (46.7\%). SIADH was the most common aetiology $(40 \%)$ followed by diuretic use $(38.6 \%)$. Chatterjee et $\mathrm{al}^{8}$ reported gastrointestinal loss as the most common cause, but have not considered SIADH in their analysis. Rahil et al ${ }^{11}$ too reported extra-renal losses as the commonest aetiology. Chowdhury et $\mathrm{al}^{13}$ reported chronic liver disease as the top cause, but selection of only ICU patients may explain the findings. Rao et al ${ }^{10}$ reported SIADH as the commonest cause in their hospital based descriptive study. This implies that different patient populations present with different aetiologies, which should be kept in mind while managing a patient with hyponatraemia.

Congestive Heart Failure (CHF), cirrhosis liver and nephrotic syndrome are the major diagnostic considerations in hypervolaemic hyponatraemia. In our study, 9 patients had CHF with mean age 66.8 years and mean serum sodium $123.28 \mathrm{mEq} / \mathrm{L}$ with male preponderance. Common comorbidities were Hypertension (HTN), Diabetes Mellitus (DM) and Ischaemic Heart Disease (IHD). Two of them $(22.2 \%)$ had serum sodium $\leq 120 \mathrm{mEq} / \mathrm{L}$. In comparison, Rawal et $\mathrm{al}^{15}$ reported a mean age of 44.25 years with male preponderance and similar mean serum sodium $(122.95$ $\mathrm{mEq} / \mathrm{L}$ ) in a sample of CHF patients having hyponatraemia (major differences include large sample size of 334 patients and cut-off value for severe hyponatraemia set at $\leq 110$ $\mathrm{mEq} / \mathrm{L}$. Cirrhosis liver was an aetiology in 16 of our patients with 6 of these having hepatic encephalopathy. All but one had a serum sodium of $<130 \mathrm{mEq} / \mathrm{L}$ and the mean value was $120 \mathrm{mEq} / \mathrm{L}$. This is consistent with the findings of Guevara et al $^{16}$ from Spain who concluded that serum sodium $<130$ $\mathrm{mEq} / \mathrm{L}$ is an independent risk factor for hepatic encephalopathy.

Only four patients had cancer: two with carcinoma sigmoid colon and one each having Hodgkin's lymphoma and meningioma. Tumour related hyponatraemia was reviewed by Onitilo et al. 17

Diuretics accounted for the second largest group; 9 patients (12\%) were on combinations containing the aldosterone inhibitor spironolactone. Arampatzis et al ${ }^{18}$ found hyponatraemia to be more common in patients on diuretics in a study on drug-induced hyponatraemia.

\section{Limitations of this Study were:}

- Nephrotic syndrome patients were not included in the study, as they are admitted under the Nephrology unit together with chronic kidney disease patients and would have skewed the patient population.

- Due to logistic constraints, patients admitted under various superspeciality departments were not considered for enrolment. Surgical patients were not included in the study.

- Serum cortisol could not be done for most patients due to logistical and financial constraints.

- Hospital acquired hyponatraemia, course in hospital, treatment options and outcomes (morbidity/mortality) were not analysed.

\section{CONCLUSION}

75 adult patients admitted in General Medicine wards having serum sodium of less than $135 \mathrm{mEq} / \mathrm{L}$ were studied. Majority of patients were above 60 years of age, male and presented with predominantly neurological symptoms. Most of the patients had euvolaemic hyponatraemia. Among risk factors, SIADH was the commonest followed by diuretics. Hyponatraemia is very common and should be sought and actively investigated in all patients, especially in the elderly and in patients who are on one or more drugs known to cause hyponatraemia.

\section{REFERENCES}

[1] Mount D. Fluid and electrolyte disturbances. In: Longo, Fauci, Kasper, et al. eds. Harrison's principles of internal medicine. $18^{\text {th }}$ edn. Vol 1. McGraw-Hill 2012:341-9.

[2] Anderson RJ. Hospital associated hyponatremia. Kidney Int 1986;29(6):1237-47.

[3] Hawkins RC. Age and gender as risk factors for hyponatremia and hypernatremia. Clin Chim Acta 2003;337(1-2):169-72.

[4] Kumar S, Berl T. Disorders of water metabolism. In: Schrier RW. edr. Atlas of diseases of the kidney. Vol 1. Philadelphia: Current Medicine Inc, 1999:1-12.

[5] Ayus JC, Negri AL, Kalantar-Zadeh K, et al. Is chronic hyponatremia a novel risk factor for hip fracture in the elderly? Nephrol Dial Transplant 2012;27(10):3725-31.

[6] Sankarpandian B, Cheng S. Fluid and electrolyte management. Chapter 9. In: Foster C, Mistry N. eds. The Washington manual of medical therapeutics. 33rd edn. Lippincott Wlliams \& Wilkins 2010:370-81.

[7] Ellison D. Disorders of sodium balance. In: Schrier RW edr. Atlas of diseases of the kidney. Vol 1. Philadelphia: Current Medicine Inc., 1999:2-13.

[8] Chatterjee N, Sengupta N, Das C, et al. A descriptive study of hyponatremia in a tertiary care hospital of Eastern India. Indian J Endocrinol Metab 2012;16(2):288-91.

[9] Waikar SS, Mount DB, Curhan GC. Mortality after hospitalization with mild, moderate and severe hyponatremia. Am J Med 2009;122(9):857-65.

[10] Rao MY, Sudhir U, Anil Kumar T, et al. Hospital based descriptive study of symptomatic hyponatremia in elderly patients. J Assoc Physicians India 2010;58:667-9. 
[11] Rahil AI, Khan FY, Al Badri MM. Clinical profile of hyponatraemia in adult patients admitted to Hamad general hospital, Qatar: experience with 53 cases. Journal of Clinical and Diagnostic Research 2009;3(2):1419-25.

[12] Agarwal SM, Agarwal A. A comparative study of the clinic-aetiological profile of hyponatremia at presentation with that developing in the hospital. Indian J Med Res 2011;134:118-22.

[13] Chowdhury R, Samanta T, Pan K, et al. Can hyponatraemia predict mortality in intensive care unit patients: a prospective study in a tertiary care hospital of Kolkata. Int J Med Pharm Sci 2013;3(7):2630.

[14] Shapiro DS, Sonnenblick M, Galperin I, et al. Severe hyponatraemia in elderly hospitalized patients: prevalence, aetiology and outcome. Intern Med J 2010;40(8):574-80.
[15] Rawal JR, Joshi HS, Jain SR, et al. Evaluation of hyponatremia in heart failure patients admitted in critical care unit: single centre experience. IJABMS 2013;15b(21):20-4.

[16] Guevara M, Baccaro ME, Torre A, et al. Hyponatremia is a risk factor of hepatic encephalopathy in patients with cirrhosis: a prospective study with timedependent analysis. Am J Gastroenterol 2009;104(6):1382-9.

[17] Onitilo AA, Ebenezer K, Doi SAR. Tumour related hyponatremia. Clin Med Res 2007;5(4):228-37.

[18] Arampatzis S, Funk GC, Leichtle AB, et al. Impact of diuretic therapy associated electrolyte disorders present on admission to the emergency department: a cross-sectional analysis. BMC Med 2013;11:83. 